\title{
A review of public health, social and ethical implications of voluntary medical male circumcision programs for HIV prevention in sub-Saharan Africa
}

\author{
Winnie Kavulani Luseno (iD ${ }^{1,4 凶}$, Stuart Rennie (iD ${ }^{2,3,4}$ and Adam Gilbertson (iD)
}

(c) The Author(s), under exclusive licence to Springer Nature Limited 2021

Ideally, the benefits of public health interventions should outweigh any associated harms, burdens, and adverse unintended consequences. The intended benefit of voluntary medical male circumcision (VMMC) programs in eastern and southern Africa (ESA) is the reduction of HIV infections. We review the literature for evidence of reductions in HIV incidence, evaluate the extent to which decreases in HIV incidence can be reasonably attributed to VMMC programs, and summarize social harms and ethical concerns associated with these programs. Review findings suggest that HIV incidence had been declining across ESA since before the largescale rollout of VMMC as a public health intervention, and that this decline may be due to the combined effects of HIV prevention and treatment interventions, such as expanded antiretroviral therapy. The independent effect of VMMC programs in reducing HIV infections at the population level remains unknown. On the other hand, VMMC-associated evidence is increasing for the existence of negative social impacts such as stigmatization and/or discrimination, and ethically problematic practices, including lack of informed consent. We conclude that the relationship between the benefits and burdens of VMMC programs may be more unfavorable than what has been commonly suggested by proponents of global VMMC campaigns.

IJIR: Your Sexual Medicine Journal; https://doi.org/10.1038/s41443-021-00484-x

\section{INTRODUCTION}

In 2007, the World Health Organization (WHO) and Joint United Nations Program on HIV/AIDS (UNAIDS) recommended voluntary medical male circumcision (VMMC) be offered as part of a comprehensive package of HIV prevention interventions in high prevalence settings, particularly in eastern and southern Africa (ESA) [1]. The recommendation was based on results from three randomized controlled trials (RCTs) conducted during the early to mid-2000s in Kenya, South Africa, and Uganda which showed reductions of $50-60 \%$ in the risk of female-to-male transmission of HIV among circumcised men compared with non-circumcised men [2-4]. In addition to medical male circumcision, WHO and UNAIDS recommended that the comprehensive HIV prevention package include safer sex education, condom education and provision, HIV testing, linkage to care and treatment if found positive, and management of sexually transmitted infections (STIs) [1]. Currently, 15 ESA countries are targeted as priorities for VMMC programs (Botswana, Eswatini, Ethiopia, Kenya, Lesotho, Malawi, Mozambique, Namibia, Rwanda, South Africa, South Sudan, Uganda, Tanzania, Zambia, and Zimbabwe) [5].

The goal of the rapid and urgent scale-up of VMMC programs in these 15 priority ESA countries was to reduce HIV infections in sub-Saharan Africa [1]. In this paper, we review the literature for evidence that VMMC has led to realized reductions in HIV incidence. We also evaluate the extent to which decreases in
HIV incidence can be attributed to VMMC versus other interventions (e.g., antiretroviral therapy [ART]). Additionally, we summarize findings of the societal "side-effects" of VMMC, as well as the main ethical challenges associated with these programs.

Previous reviews have focused on the barriers and facilitators of VMMC uptake to inform the development of effective interventions to increase service uptake [6], analyzed the effectiveness of economic compensation and incentives to increase VMMC uptake among older men to inform VMMC demand creation programs [7], and synthesized the evidence on best practices for the delivery of adolescent VMMC services [8]. Our paper builds on a recent review [9], which examined the impact of circumcision on the risk of HIV infection among heterosexual men in varying epidemic contexts, including men in high HIV incidence cohorts, community-based cohorts with stable circumcision prevalence, and community-based cohorts during VMMC scale-up. In this paper, we provide a 'contextual' or 'realistic' evaluation of VMMC programs in ESA priority countries that takes a balanced approach in considering the benefits and harms of the public health intervention. This is in keeping with recent recommendations for program evaluation to examine a range of factors, including those that are external to program intentions and activities, that may have contributed to the outcome. Failure to do so may misleadingly magnify the contribution of the program to the intended outcome $[10,11]$.

\footnotetext{
${ }^{1}$ Pacific Institute for Research and Evaluation (PIRE), Chapel Hill, NC, USA. ${ }^{2}$ Department of Social Medicine, University of North Carolina, Chapel Hill, NC, USA ${ }^{3}$ UNC Center for Bioethics, University of North Carolina, Chapel Hill, NC, USA. ${ }^{4}$ These authors contributed equally: Winnie Kavulani Luseno, Stuart Rennie, Adam Gilbertson. email: wluseno@PIRE.org
} 


\section{METHODS}

We conducted systematic and non-systematic searches, including gray literature, to identify publications to include in our review. We divided our review of the literature into four sections as follows: Evidence of HIV infections decreasing in the priority ESA countries; role of VMMC in reductions in HIV incidence; The unintended consequences of VMMC as a public health intervention in ESA; Main ethical dimensions of VMMC programs. For the section on the evidence of reductions in HIV incidence, we used epidemiological reports from UNAIDS and the Global Burden of Diseases, Injuries, and Risk Factors (GBD) Study. For the section on the role of VMMC in reducing HIV incidence, we used UNAIDS data and relevant peer-reviewed papers in the published literature. The peer-reviewed papers were obtained through literature searches in PubMed and EBSCOHOST for VMMC-related studies conducted in the 15 ESA priority countries. EBSCOHost included the databases Biomedical Reference Collection: Corporate; E-Journals; GreenFILE; Library, Information Science \& Technology Abstracts; MEDLINE Complete; APA PsycArticles; Psychology and Behavioral Sciences Collection; APA Psyclnfo; and SocINDEX with Full Text. Our searches were conducted in December 2020 and limited to articles published in English between 2009 and 2020. We excluded studies published in 2008 or earlier because those would have probably used studies/data prior to VMMC being implemented as policy and therefore would not tell us whether reductions in HIV incidence observed in priority countries can be attributed to the VMMC campaign. We retained five articles from longitudinal studies that contained primary data on HIV incidence in heterosexual men by circumcision status.

For the sections on the unintended consequences of VMMC and ethical considerations, we conducted a review of publications with findings suggesting potential harms associated with program implementation. To capture social science literature related to VMMC programs, we made searches of PubMed and Google Scholar over the period of 2005-2021 using relevant search terms in addition to the research databases we have from working for 14 years in the field. Additional studies were identified by reviewing articles' bibliography sections.

\section{Review of the evidence}

Evidence of HIV infections decreasing in the priority ESA countries. Overall, although trajectories differ across countries, HIV incidence in sub-Saharan Africa peaked in 1997 and has since trended downward [12]. Until 2007, infection rates decreased in most of sub-Saharan Africa, including among (at the time) nine priority ESA countries, while rates increased in eSwatini, Lesotho, Mozambique, Namibia, South Africa, and South Sudan (see Table 1) [13]. By 2017, rates of new infections were declining in all 15 priority countries, although at slower rates in Ethiopia, Kenya, Tanzania, and Zimbabwe [13]. These trends are supported by data from UNAIDS which show declines in HIV incidence trajectories between 2000 and 2019 in almost all the priority countries. Between 2010 and 2019, new infections decreased in almost all priority countries, except South Sudan, by $15-66 \%$ (see Table 1) [14]. In South Sudan, although rates of new infections declined between 2007 and 2017, the data suggest an overall 17\% increase of new HIV cases in the country since 2010.

Although new HIV infections have remained consistently higher among women than men in sub-Saharan Africa, UNAIDS data show that new infections among both groups have been declining since 2000 [14]. Data from almost all the priority ESA countries show declines in new HIV infections among women and men between 2010 and 2019. The exception is South Sudan, where HIV incidence among women and men increased during that period [14].

\section{Role of VMMC in reductions in HIV incidence}

The roll-out of VMMC programs began in 2008 in five priority countries: eSwatini, Kenya, Malawi, South Africa, and Zambia (see
Table 1. Change in new HIV infections in the priority ESA countries.

\begin{tabular}{|c|c|c|c|}
\hline \multirow[t]{2}{*}{ Country } & \multicolumn{2}{|c|}{$\begin{array}{l}\text { Annualized rate of change in new } \\
\text { infections }(95 \% \text { uncertainty } \\
\text { interval) })^{\mathrm{a}}\end{array}$} & \multirow[t]{2}{*}{$\begin{array}{l}\text { Change in new } \\
\text { HIV infections } \\
\text { since } 2010^{\mathrm{b}}\end{array}$} \\
\hline & 1990-2007 & 2007-2017 & \\
\hline \multirow[t]{2}{*}{ Botswana } & $-3.1 \%$ & $-5.3 \%$ & \multirow[t]{2}{*}{$-34 \%$} \\
\hline & $(-4.5$ to -1.8$)$ & $(-9.1$ to -1.7$)$ & \\
\hline \multirow[t]{2}{*}{ eSwatini } & $14.2 \%$ & $-21.8 \%$ & \multirow[t]{2}{*}{$-66 \%$} \\
\hline & $(8.5-19.5)$ & $(-36.1$ to -15.1$)$ & \\
\hline \multirow[t]{2}{*}{ Ethiopia } & $-18.9 \%$ & $-1.3 \%$ & \multirow[t]{2}{*}{$-46 \%$} \\
\hline & $(-21.5$ to -16.3$)$ & ( -7.6 to 4.1$)$ & \\
\hline \multirow[t]{2}{*}{ Kenya } & $-6.1 \%$ & $-3.5 \%$ & \multirow[t]{2}{*}{$-44 \%$} \\
\hline & $(-7.5$ to -4.8$)$ & $(-6.3$ to -0.5$)$ & \\
\hline \multirow[t]{2}{*}{ Lesotho } & $2.8 \%$ & $-7.1 \%$ & \multirow[t]{2}{*}{$-45 \%$} \\
\hline & $(1.1-4.5)$ & $(-10.7$ to -4.4$)$ & \\
\hline \multirow[t]{2}{*}{ Malawi } & $-7.0 \%$ & $-10.8 \%$ & \multirow[t]{2}{*}{$-41 \%$} \\
\hline & $(-8.5$ to -5.5$)$ & $(-18.9$ to -5.3$)$ & \\
\hline \multirow[t]{2}{*}{ Mozambique } & $5.4 \%$ & $-5.2 \%$ & \multirow[t]{2}{*}{$-17 \%$} \\
\hline & $(3.5-7.5)$ & $(-9.5$ to -1.7$)$ & \\
\hline \multirow[t]{2}{*}{ Namibia } & $2.4 \%$ & $-5.8 \%$ & \multirow[t]{2}{*}{$-36 \%$} \\
\hline & $(0.8-5.1)$ & $(-10.8$ to -1.2$)$ & \\
\hline \multirow[t]{2}{*}{ Rwanda } & $-6.1 \%$ & $-7.2 \%$ & \multirow[t]{2}{*}{$-47 \%$} \\
\hline & $(-9.3$ to -2.1$)$ & $(-11.7$ to -2.5$)$ & \\
\hline \multirow[t]{2}{*}{ South Africa } & $12.8 \%$ & $-5.7 \%$ & \multirow[t]{2}{*}{$-53 \%$} \\
\hline & $(11.3-14.2)$ & $(-7.9$ to -3.8$)$ & \\
\hline \multirow[t]{2}{*}{ South Sudan } & $0.2 \%$ & $-5.7 \%$ & \multirow[t]{2}{*}{$17 \%$} \\
\hline & ( -5.4 to 9.5$)$ & $(-15.6$ to -2.9$)$ & \\
\hline \multirow[t]{2}{*}{ Tanzania } & $-8.3 \%$ & $-6.6 \%$ & \multirow[t]{2}{*}{$-19 \%$} \\
\hline & $(-10.8$ to -6.0$)$ & ( -41.9 to 7.7$)$ & \\
\hline \multirow[t]{2}{*}{ Uganda } & $-3.8 \%$ & $-11.4 \%$ & \multirow[t]{2}{*}{$-43 \%$} \\
\hline & $(-7.7$ to 0.2$)$ & ( -35.9 to 2.5$)$ & \\
\hline Zambia & $-5.4 \%$ & $-8.3 \%$ & $-15 \%$ \\
\hline & ( -6.7 to -4.2$)$ & $(-12.2$ to -4.2$)$ & \\
\hline Zimbabwe & $-8.5 \%$ & $-3.0 \%$ & $-44 \%$ \\
\hline & $(-11.0$ to -6.3$)$ & $(-40.1$ to 7.9$)$ & \\
\hline Sub- & $-2.8 \%$ & $-5.9 \%$ & \\
\hline Saharan Africa & $(-3.8$ to -1.9$)$ & $(-8.2$ to -3.6$)$ & \\
\hline Global & $-0.4 \%$ & $-3.0 \%$ & \\
\hline & $(-1.2$ to 0.3$)$ & $(-4.5$ to -1.5$)$ & \\
\hline
\end{tabular}

Sources: ${ }^{\mathrm{a}} \mathrm{GBD} 2017$ and ${ }^{\mathrm{b}}$ UNAIDS 2020.

Table 2) [5]. By 2012, the number of priority countries implementing VMMC programs had increased to 14 . South Sudan was included in 2018 as the 15th priority country.

The success of VMMC programs among the 15 priority countries is typically presented in terms of the numbers of males medically circumcised, prevalence or coverage of VMMC, and new HIV cases averted. Between 2008 and 2018, an estimated 22.6 million men were medically circumcised in the 15 priority ESA countries [5]. By 2018, South Africa, Uganda, Tanzania, and Zambia had each circumcised over two million males. During the same period, Kenya, Mozambique, Rwanda, and Zimbabwe each circumcised between one to two million males. The remaining countries had each circumcised less than one million males (see Table 2).

In 2011, UNAIDS and the U.S. President's Emergency Plan for AIDS Relief (PEPFAR) set a target goal of at least $80 \%$ VMMC 


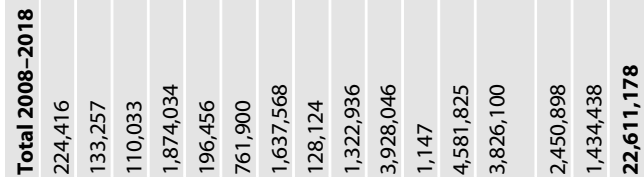

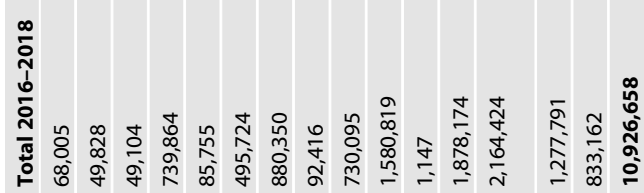

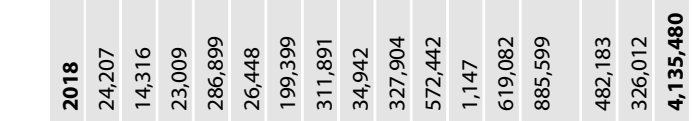

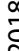

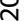

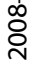

.ֶ.

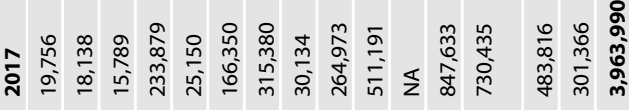

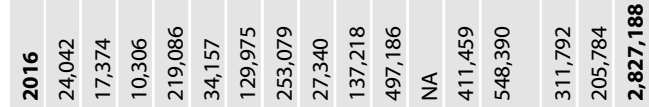

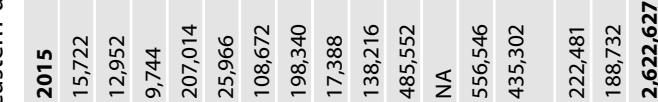

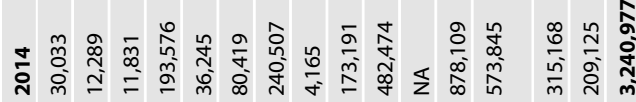

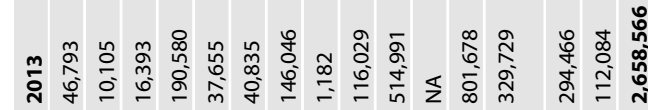

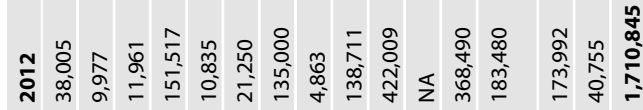
光

$\frac{\pi}{8}$

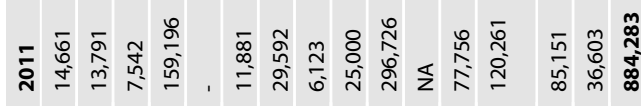

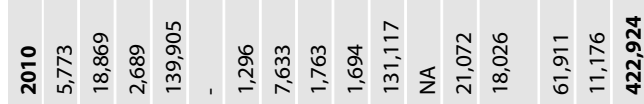

prevalence or coverage among males aged 15-49 years in the priority countries [1]. Evidence indicates that by 2017, only three priority countries (Ethiopia, Kenya, and Tanzania) had achieved the $80 \%$ coverage goal at the national level; all other priority countries had not achieved the goal [15]. In 2014, priority countries, including Kenya, started providing VMMC to boys as young as 10 years old [16]. Since then, a large proportion of VMMCs has been conducted among males under the age of 15 years [17]. However, WHO guidance no longer prioritizes this age group due to concerns about safety and informed consent [18].

Based on epidemiological modeling studies, it was expected that the 22.6 million circumcisions performed in ESA priority countries would potentially avert about 250,000 new HIV infections; $78 \%$ among men and $22 \%$ among women [5]. These estimates suggest that VMMC has a significant role in reducing HIV incidence in priority ESA countries. However, estimates of the impact of VMMC on HIV incidence have declined over time as technical aspects and assumptions of the models have changed, underscoring the limitations of basing key policy decisions on modeling studies $[19,20]$. For example, early models incorrectly assumed uniform uptake of VMMC among males of different age groups and a steady or gradual decline in HIV incidence in priority ESA countries. Also, the early models did not account for the impact of the expanding use of ART and pre-exposure prophylaxis (PrEP) on HIV incidence [19]. Limitations of modeling studies continue to be identified in recent publications with attendant declines in the estimated effect of VMMC on HIV incidence [21].

As summarized above, surveillance data indicate that HIV incidence was declining in most of the priority ESA countries before the large-scale rollout of VMMC began [12-14]. Moreover, these data provide no evidence of substantial changes in the downward trending trajectories of HIV incidence to support the argument that VMMC has had a significant role in reducing HIV infections in priority countries. Although a recent systematic review and meta-analysis concluded that VMMC is "an important evidence-based intervention for the control of generalized HIV epidemics", [9] as presented below, we did not find convincing evidence that VMMC has had a significant effect on reducing HIV incidence at the population level.

Two population-based prospective studies in Uganda [22] and South Africa [23] assessed the impact of combination interventions on HIV incidence. Findings from both studies indicate that ART use, viral load suppression, and VMMC coverage all increased in the study settings over their respective research periods. HIV prevalence and incidence also decreased in both settings among men and women (see Table 3). Additionally, regression analysis using data from Uganda found that male circumcision was associated with decreased HIV incidence among men [22]. Another study to assess the impact of VMMC on male HIV risk in Uganda also found that male circumcision was associated with a lower risk of incident HIV infection [24]. However, although reductions are larger among men who are circumcised, study findings indicate that HIV incidence rates are also declining among men who are non-circumcised [23, 24]. While the reductions in HIV incidence among women and non-circumcised men may be due to indirect protection afforded by VMMC (i.e., circumcised men not acquiring and transmitting HIV), it is also possible that other factors (e.g., expanded ART coverage) may be contributing to the reduction of new HIV cases in the priority countries.

Borgdorff et al. [25] used data from a health and demographic surveillance system (HDSS) in Kenya to determine trends in HIV prevalence and incidence between 2011 and 2016. They found that, overall, HIV incidence declined over the surveillance period. They also found that while having a circumcised male partner was protective for women and girls, the protective effect of circumcision was not significant for incident HIV infection among men and boys. Borgdorff et al. [25] concluded that "the decline of HIV 
Table 3. Summary of findings from studies examining the effectiveness of VMMC and ART in reducing HIV incidence.

\section{First author (year)/study purpose}

Kagaayi et al. (2019) [22]

To assess the impact of combination

HIV interventions on HIV incidence in four HIV-hyperendemic communities.

Loevinsohn et al. (2020) [24]

To assess the impact of a PEPFARsupported

VMMC program on the risk of male HIV acquisition

over time.

\section{Country/ study period}

Uganda

2011-2017

Uganda

2008-2016

\section{Botswana}

2013-2018

To determine whether and to what degree a community-based intervention to maximize HIV testing and case identification, linkage to care, early (expanded) ART, and male circumcision could reduce the population-level incidence of HIV infection.
Vandormael et al. (2019) [23]

To quantify sex-specific trends in HIV incidence following changes in ART coverage, prevalence of detectable viremia, condom use, and male circumcision.

\section{Research design/sample}

Open population-based prospective cohort study

Males and females aged $15-49$ years $N=8942(52 \%$ male $)$

Open population-based prospective cohort study

Analytical sample restricted to nonMuslim HIV uninfected and uncircumcised men at study entry $N=3916$ men

Five survey rounds denoted as 13-17

Pair-matched communityrandomized trial Residents from random sample of $\sim 20 \%$ of households in each community.

$N=4,487$ enrolled in HIV incidence cohort in each group (intervention and control); $60 \%$ were female.
South Africa 2005-2017
Prospective cohort of repeat HIV testers in a population-based HIV testing platform $N=22,239 ; 57 \%$ women

\section{Results}

$\uparrow$ ART use from $16 \%$ at baseline to $82 \%$ at final survey.

$\uparrow$ Population viral load suppression among HIV + from $34 \%$ at baseline to $80 \%$ at final survey.

$\uparrow$ Male circumcision coverage from 35\% at baseline to $65 \%$ at final survey.

$\downarrow$ HIV prevalence from $41 \%$ at baseline to $37 \%$ at final survey.

$\downarrow$ HIV incidence from 3.43 per 100 personyears $(95 \% \mathrm{Cl}, 2.45-4.67)$ at baseline to 1.59 per 100 person-years $(95 \% \mathrm{Cl}, 1.19-2.07)$ at final survey.

Male circumcision associated with decreased HIV incidence.

$34 \%$ of eligible men were circumcised between 2008 and 2016.

$\downarrow$ HIV incidence in circumcised men $(0.86$ infections per 100 person-years for survey rounds $13-14$ vs 0.30 infections per 100 person-years for survey rounds 15-17; men who were non-circumcised (1.33 infections per 100 person-years for survey rounds $13-14$ vs 0.74 infections per 100 personyears for survey rounds $15-17$.

VMMC associated with $51 \%$ lower risk of incident HIV infection.

$\downarrow$ HIV incidence ratio in intervention group compared with standard-care group. $\uparrow$ (Nonsignificant) effect of intervention than standard care on incidence of HIV infection among men.

$\uparrow$ Increase in percentage of virally suppressed HIV-positive participants in intervention communities (from 70 to $88 \%$ ) than in standard-care communities (from 75 to $83 \%$ ) (relative risk, $1.12 ; 95 \% \mathrm{Cl}$, 1.09-1.16).

Among HIV+ not receiving ART at enrollment, median time to initiation of ART was 69 days in the intervention group compared to 367 days in the standardcare group.

$\uparrow$ in \% of HIV - men aged 16-49 years who reported being circumcised from $30 \%$ at baseline to $40 \%$ at trial end in the intervention group, as compared with an increase from 33 to $35 \%$ in the standardcare group (relative risk, 1.26; $95 \% \mathrm{Cl}$, 1.17-1.35).

$\downarrow$ HIV incidence rates (IRs) when oppositesex ART coverage surpassed $35 \%$ and ART eligibility criteria were removed in 2016. $\downarrow$ HIV incidence between 2012 and 2017 among men from $2.49(95 \% \mathrm{Cl}, 1.83-3.37)$ to $1.01(95 \% \mathrm{Cl}, 0.58-1.76)$ seroconversion events per 100 person-years. $\downarrow$ HIV incidence between 2014 and 2017 among females from $4.89(95 \% \mathrm{Cl}, 4.09$, $5.84)$ to $3.06(95 \% \mathrm{Cl}, 2.38-3.94)$ seroconversion events per 100 personyears.

$\uparrow$ ART coverage among HIV + women from $2.1 \%$ in 2005 to $54.6 \%$ in 2017 and among $\mathrm{HIV}+$ men from $1.5 \%$ in 2005 to $38.4 \%$ in 2017.

$\downarrow$ Population prevalence of detectable viremia among women from $72.8 \%$ in 2011 to $55.3 \%$ in 2014 and among men from 
Table 3 continued

First author (year)/study purpose

Borgdorff et al. (2018) [25]

To determine the trends in HIV

prevalence and incidence.

\author{
Country/ \\ study period
}

Kenya

2011-2016
Research design/sample

Secondary analysis of data from a health and demographic surveillance system (HDSS) in which home-based counseling and testing (BCT) surveys have been done since 2011 , to increase coverage of HIV control interventions.

Age 13 and older

$N=12,606$ included in HIV incidence analysis

\author{
Results \\ $77.8 \%$ in 2011 to $67.2 \%$ in 2014. \\ $\uparrow$ Self-reported circumcision among men \\ from 3.0 to $32.9 \%$ between 2009-2016. \\ $\downarrow$ HIV IR between 2012 and 2016 from 1.24 \\ (95\% Cl, 0.57-2.69) to 0.5 (95\% Cl, 0.16-1.57) \\ events per100 person-years among \\ circumcised men and from $3.01(95 \% \mathrm{Cl}$, \\ $2.16-4.18)$ to $1.73(95 \% \mathrm{Cl}, 1.01-2.97)$ events \\ per100 person-years among \\ uncircumcised men. \\ $\downarrow$ Adjusted incidence rate ratio among \\ circumcised men compared with \\ uncircumcised men and among \\ circumcised and uncircumcised men \\ compared with women.
}

$\downarrow$ HIV incidence from $11.1(95 \% \mathrm{Cl}, 9.1-13.1)$ per 1000 p-ys in $2011-12$ to $5.7 \%(95 \% \mathrm{Cl}$, 4.6-6.9) per $1000 \mathrm{p}$-ys in 2012-16.

$\downarrow$ Adjusted HIV incidence ratio $(0.5,95 \% \mathrm{Cl}$, 0.2-1.0) among females with a circumcised male partner than with uncircumcised male partner.

$\downarrow$ (Non-significant) unadjusted HIV

incidence ratio $(0.7,95 \% \mathrm{Cl}, 0.4-1.1)$ among circumcised males compared to uncircumcised males. prevalence and incidence cannot be directly attributed to increasing ART and VMMC coverage. Other explanatory factors might include the natural history of the HIV epidemic in eastern Africa, which showed declines of HIV incidence even before the onset of large-scale ART use and expanding VMMC coverage". This claim is consistent with the data presented in the preceding section and, as further illustrated below by Makhema et al. [26], suggests that there are likely many factors responsible for reductions in HIV incidence where they occur, and it is simplifying and misleading to assert (since the evidence is weak) that VMMC initiatives are a major determinant among these factors.

Makhema et al. [26] conducted a pair-matched community randomized trial to examine whether and to what degree a combination intervention to maximize HIV testing and case identification, linkage to care, early (expanded) ART, and male circumcision could reduce the population-level incidence of HIV infection in Botswana. Compared to baseline, at study conclusion, they found a significantly greater increase in the percentage of virally suppressed HIV-positive participants and shorter time to ART initiation in intervention communities than in standard-care communities. They also observed a larger increase in the percentage of HIV-negative men who reported being circumcised in the intervention group than the standard-care group. However, in the Discussion section, the authors state that while the reduction in HIV incidence in the intervention group may be due to the intervention, they were "...unable to directly determine which specific intervention or interventions were most important in reducing the incidence of HIV infection". Additionally, "[g]iven the small number of men who underwent circumcision (approx. $50 \%)$ by trial end, it is unlikely that male circumcision contributed substantially".

A key limitation of studies conducted to date is that none were designed to measure the independent effect of VMMC programs on population-level HIV incidence. The studies indicate that combination HIV interventions are effective in reducing HIV incidence. However, the studies do not contribute knowledge about the specific effect of VMMC on the reduction of HIV incidence at the population level, suggesting a need for appropriately designed, rigorous studies to address this knowledge gap.

\section{The unintended consequences of VMMC as a public health intervention in ESA}

Our literature review not only revealed weak evidence for the benefit commonly associated with VMMC programs (lowered HIV incidence), it also exposed various concerns associated with VMMC program implementation. Divided into three categories, these unintended consequences include adverse events, risk compensation, and social/cultural impacts.

Adverse events. Adverse events are negative health outcomes associated with accident or provider error [27]. Concerning VMMC, adverse events are generally rare. Within the three RCTs [2-4] that provided the basis for the recommendation that VMMC be implemented as an HIV prevention intervention [28], the rate of adverse events was $1.5-7.6 \%$ [29]. As reported, these included pain, wound reopening, bleeding, hematoma, swelling, issues with anesthetics, erectile dysfunction, unhappiness with appearance, and infection [29]. For adolescents, the risk of urethrocutaneous fistulas resulting from circumcision is an additional concern [30]. Rarer, but more serious injuries include damage to or amputation of the glans [31], Fournier's gangrene [32], and deaths resulting from tetanus infections [33,34]. To avoid or mitigate adverse events in VMMC programs, researchers have pointed out the need to improve the quality of VMMC services. Their suggestions include increasing parental engagement among adolescent clients $[35,36]$, managing targets to ensure service providers are not overwhelmed by demand [36, 37], enhancing preoperative screening $[36,38]$, ensuring consistent and thorough counseling to ensure patients know how to care for themselves [39], and improving patient access to post-operative medical care [40].

Risk compensation. From early in the drive to promote VMMC, there existed concerns about risk compensation [3, 4, 29, 41-44]. Risk compensation (or disinhibition) refers to the worry that those who undergo a preventive intervention may engage in behaviors 
that put them at risk because they feel protected [45]. Much evidence exists suggesting that post-medical male circumcision risk compensation concerns are unfounded [3, 4, 42, 46-49]. This includes results from studies that analyzed self-reported data and did not find statistically significant changes in risk compensation among men at three [50] months and at one $[42,51]$, two $[52,53]$, and three years post-circumcision [54]. Researchers have also reported decreases in risk behaviors following VMMC [4, 51, 52], including increased condom use $[55,56]$. These findings are expected [57] given that the RCTs and subsequent implementation efforts provided HIV risk behavior education as an intervention component. In Kenya, a decrease in risk behaviors was observed among both men who became circumcised and those who chose to remain non-circumcised [51]. Another study reported no significant risk compensation, even when the potential effects of risk reduction education were excluded [46].

Other studies, however, report having found evidence of risk compensation. For instance, in Zambia circumcised men aged 15-29 have been found to engage in riskier behaviors in terms of having more extramarital partners compared to non-circumcised men $(11.1 \%$ circumcised vs $8.7 \%$ non-circumcised; relative risk: 1.278; $p=0.045$ ) [58]. Although the differences were not statistically significant, rates were higher among circumcised than non-circumcised men of having two or more partners (circumcised $24.5 \%$ vs non-circumcised $22.4 \%$ ) and using commercial sex services (circumcised $2.1 \%$ vs non-circumcised $1.9 \%$ ) [58]. Interestingly, one study found increased risk-taking among those who underwent circumcision, but also that belief in the protectiveness of circumcision led to less risky behaviors [59]. Even in the early study conducted by Auvert et al. [2], statistically, significant increases in the mean number of sex partners among those who underwent circumcision were observed (5.9 versus 5.0, $p<0.001$ between months four and 12 and 7.5 versus $6.4, p=0.0015$ between months 13 and 21), suggesting at least the potential for risk compensation.

Nonetheless, a recently published systematic review and metaanalysis of risk compensation among heterosexual men [48] have led some to conclude definitively that concerns about risk compensation associated with VMMC are unfounded [49]. Yet, even if we leave aside the well-known issues related to social desirability bias [60-62] associated with measures that rely on selfreported sexual behaviors (as these studies do), this systematic review shows a range of effects on post-circumcision risk compensation (positive, negative, and neutral), depending on context. In other words, the data presented by Gao et al. [48] show that risk compensation is an issue of concern in some contexts, but not in others. This suggests that there are likely some factors, not yet well understood, that may foster post-circumcision risk compensation in some settings, while inhibiting it in other settings.

Added to this, smaller, qualitative, and survey-based studies provide greater context for how changes in behavior and attitudes post-medical male circumcision may affect risk behaviors [63]. For example, one study reported men engaging in unprotected sex too soon after VMMC due to cultural beliefs concerning sexual cleansing and/or misunderstandings related to what it meant to be fully healed [43]. Worryingly, a cross-sectional survey study conducted in Botswana, Namibia, and Swaziland found that 13\% of young men and $10 \%$ of young women incorrectly believed that circumcision provides men with $100 \%$ protection from HIV [64]. Similarly, a study of risk perceptions among South African women suggested that women who were aware of VMMC's protective effect also believed circumcised men had less need for condoms and posed less HIV risk for women [65]. Finally, researchers have reported HIV behavioral risk compensation among traditionally circumcised South African men. As they explain, the influence of the promotion of VMMC for HIV prevention for non-circumcised men may have harmful impacts via increased risk behaviors among men who were circumcised without the benefit of risk reduction counseling [66]. This suggests the need for risk reduction education for all circumcised men [67]. In summary, broad claims that VMMC does not lead to risk compensation should be examined critically, as behavioral responses to being medically circumcised may differ by setting, and some dimensions of sexual behavior (such as the number of partners) may be less affected by VMMC than others (such as condom use).

Social and cultural impacts. Social and cultural impacts ranging from the individual level to that of community and society are important, yet less widely considered potential unintended consequences of VMMC campaigns. For males who remain noncircumcised but live within contexts where VMMC campaigns have been successful, social impacts may include stigmatization and/or discrimination [35, 36]. Importantly, VMMC programs target traditionally non-circumcising communities, within which some people oppose circumcision for cultural reasons. The promotion of VMMC among these groups may constitute the advancement of a "new bodily norm", which could impact people's sense of cultural or ethnic identity and autonomy [68], as well as how they are perceived as an ethnic group by others [69]. Additionally, some efforts to promote and implement VMMC frame tradition and culture as "barriers" to be overcome in the name of "progress." As such, VMMC campaigns, both primarily funded and largely implemented by Western actors or surrogates, have been argued to represent a kind of "cultural imperialism" within which local customs and systems of meaning surrounding circumcision-or non-circumcision-are overridden by a narrow biomedical lens [69]. It seems hardly mere coincidence that the United States, where male circumcision is a more prevalent and accepted cultural practice compared to other countries in the global north $[70,71]$, is the country that has made the most significant contributions to the advent of VMMC as an HIV prevention intervention, as well as to its continued funding and implementation across much of sub-Saharan Africa [72].

Additionally, there is the issue of gender equity: while women are socially, politically, and physiologically more vulnerable to HIV infection, VMMC campaigns focus on men and prioritize the prevention of female-to-male transmission, with prevention among women existing as an assumed, secondary, "knock-on" benefit of this intervention [73-75], despite direct evidence to the contrary. For instance, the sole randomized trial designed to test the hypothesis that male circumcision will reduce male-to-female HIV transmission (see Wawer et al.) [76] was terminated early after the female partners of circumcised men were found to have a $8.3 \%$ greater risk of infection over 24 months compared to the female partners of non-circumcised men in the control group. It could be (and has) been argued that the increased risk for the partners of circumcised men observed in this study can be explained by the premature resumption of sex before the completion of post-circumcision healing and therefore, could be avoided within VMMC implementation by risk reduction counseling and educative efforts. However, it is important to note that risk reduction counseling, condoms, and repeated instructions were provided within this trial, yet there was still an observed increase in risk for the female partners of circumcised men [76]. It seems somewhat misguided to assume that risk reduction counseling will be better or more effective in the less controlled real-world conditions of VMMC scale-up than in a controlled clinical trial setting. Moreover, if counseling against risk behaviors is key to the effectiveness of the intervention, then why circumcise at all? Would it not make more sense to use sexual risk behavior counseling as the primary intervention, given that regular condom use, reduction in risk of partners, etc., is more effective than circumcision, and removes the need for surgery? Regardless of one's interpretation of the Wawer et al. trial [76], what seems clear is that HIV prevention efforts that do not 
prioritize social, cultural, and political factors, including gender dynamics, may sidestep, obscure, or exacerbate many key structural factors known to drive the epidemic, or misdirect attention and funding in such a way as to result in more harm than good.

Furthermore, there exists the potential for a loss of public trust in the healthcare system, the institutions that exist to promote public health (e.g., PEPFAR, non-governmental organizations [NGOs], and their local implementation partners), and other future public health interventions [72]. The concern is that if people feel harmed, wronged, or misled by VMMC's proponents or implementers, they may become generally disinclined to engage with local healthcare or accept or participate in future public health campaigns. Such an outcome could be an unintentional, yet disastrous legacy of efforts to circumcise across ESA. Preservation of public trust has been shown to be crucial in Africa in relation to other infectious disease epidemics, including COVID-19 [77-79]. While no study has yet made a thorough assessment of the social/ cultural impacts of VMMC for HIV prevention in Africa, these examples do suggest harms that may accumulate through continued efforts to promote this public health initiative given the ongoing uncertainty surrounding the independent contribution of VMMC to reducing new HIV infections, when considered alongside other measures.

\section{Main ethical dimensions of VMMC programs}

Ethical debates have arisen concerning the production of scientific evidence for VMMC reducing HIV transmission, including the RCTs in Africa [80-82], the process of transforming scientific evidence into HIV prevention policies [83, 84], and the translation of these policies in actual VMMC programs [36, 37]. Here we focus on four key ethical concerns in VMMC program implementation.

Voluntary informed consent. While some public health interventions are compulsory, the ' $\mathrm{V}$ ' in VMMC implies that program participants can freely choose medical circumcision based on adequate information and understanding. However, the quality of consent in VMMC program implementation has been questioned on various grounds. As mentioned below, VMMC initiatives have targeted youths aged 15 and younger, sometimes without parental or guardian involvement. It is to be expected that youths may be challenged to freely choose and comprehend the significance of VMMC, particularly those from disadvantaged backgrounds who may lack familiarity with being asked to choose for medical procedures, as some studies have borne out [40]. Concerns have also been raised about aggressive persuasion strategies, including various forms of "demand creation" (including the use of economic incentives), peer pressure, and stigmatization of the non-circumcised $[85,86]$. Results of studies on information disclosure and comprehension in VMMC consent processes are mixed, with some studies indicating that participants generally understand the nature and implications of VMMC [87], while others suggest the information provided emphasizes benefits over risks [88] and that participants have a poor understanding of key elements [35]. For example, prospective volunteers for VMMC are typically told that circumcision 'will reduce their risk of acquiring HIV by $60 \%$ ', without further explaining that this is a $60 \%$ reduction in relative risk, i.e., relative to the absolute HIV risk where the original clinical trials were conducted nearly two decades ago. Volunteers are highly unlikely to know this key background information or that the absolute HIV risk may in fact now be quite small in their own communities.

Preventive genital surgery with minors. VMMC programs have followed international guidance in officially offering circumcision to adolescents [89], though in practice children from the age of 10 have been included [90]. Recently, safety issues in VMMC with boys under the age of 15 led PEPFAR to discontinue funding in its programs for this age group [30], though it is likely that 'preadolescent' VMMC still takes place. Beyond the issue of physical (and potential psychological) [35] harm, most ethical issues revolve around the surgical removal of healthy genital tissue for HIV prevention purposes from adolescents in low- and middleincome country (LMIC) contexts. For reasons already given regarding informed consent, these adolescents (relative to adults) are likely less able to grasp the significance of the procedure or to decide autonomously in the face of influences from caregivers, peers, or other authorities [91]. Some adolescents are circumcised for prevention purposes without caregiver permission in jurisdictions where such permission is required [35, 92]; other studies suggest parental guidance in adolescent HIV prevention decisionmaking is often hindered by cultural and gender norms and lack of appropriate knowledge regarding HIV [93].

Program imperatives and unintended consequences. In VMMC programs, the ultimate goal of reducing HIV incidence is translated into specific numbers of circumcisions to be performed within a certain time period [36]. As mentioned above, vigorous pursuit of VMMC targets leads to several unintended and undesirable consequences. These consequences are also ethically questionable to the extent that they are unintended but not unexpected [94], and there are reasons to believe that some of these consequences should have been anticipated and mitigated.

First, it is well-known that purposive social actions regularly lead to unintended (including harmful) outcomes [95], and there is a substantial literature on unintended consequences connected with public health interventions [96]. Second, some effects connected to VMMC programs now being reported were identified by stakeholders prior to them being designed and implemented $[97,98]$. VMMC programs are therefore vulnerable to the following ethical criticism: the strong focus on fulfilling circumcision targets led key stakeholders (e.g., funders and program implementers) to downplay the moral significance of reasonably expectable program-related harms. This contrasts with official WHO ethical guidance that states: "Taking a human rightsbased approach to the development or expansion of male circumcision services requires measures that ensure that the procedure can be carried out safely, under conditions of informed consent, and without coercion or discrimination" [89].

Ethics of interventions that change social norms. VMMC differs significantly from traditional (ritual) circumcision in terms of its symbolic, cultural, and political significance. Promoting VMMC for HIV prevention, therefore, requires changing important norms for non-circumcising and traditionally circumcising communities and raises issues of social harm and justice. VMMC can disrupt meaningful distinctions and political relationships between ethnic groups, and can have adverse outcomes for women, and gender and sex dynamics, particularly if VMMC is promoted as a way of being a 'real' man $[68,99]$. In general, deliberately attempting to change social norms for public health purposes is ethically controversial, not just because of likely unintended consequences (see above) but also due to the underlying assumption that public health goals should override traditional values. The assumption's soundness is unclear in the case of VMMC, particularly in LMICs where (increasingly) HIV is not the most pressing public health problem.

\section{CONCLUDING REMARKS}

Epidemiological data indicate that HIV incidence rates were already declining among both females and males in most ESA priority countries at the time VMMC programs were implemented in 2008. Incidence rates have continued to decline with limited evidence that the introduction of VMMC changed the rate of decline in priority countries. Additionally, we did not find 
convincing evidence from studies assessing the effectiveness of combination HIV prevention interventions of a consistent, significant, and independent effect of VMMC on reducing population-level HIV incidence. This is not to say that VMMC programs have had no effect. Instead, we mean only to emphasize that clear evidence of the effect of VMMC on HIV incidence at the population level independent of other possible causal factors (e.g., expanded ART among HIV-infected individuals) does not currently exist.

According to influential public health ethics frameworks, ineffective public health interventions are ethically problematic because they have a poor risk/benefit profile and waste resources [100]. To the extent that their effectiveness in reducing HIV incidence remains unclear, the ethical justification of VMMC programs is more precarious than their proponents suggest. This precariousness opens the door for more general ethical critiques, e.g., that VMMC initiatives (especially in Africa) are manifestations of Western neocolonialism in global public health [69].

\section{REFERENCES}

1. UNAIDS/WHO. Joint strategic action framework to accelerate the scale-up of voluntary medical male circumcision for HIV prevention in Eastern and Southern Africa. Geneva: UNAIDS/WHO; 2011.

2. Auvert B, Taljaard D, Lagarde E, Sobngwi-Tambekou J, Sitta R, Puren A. Randomized, controlled intervention trial of male circumcision for reduction of HIV infection risk: the ANRS 1265 trial. PLoS Med. 2005;3:e226.

3. Gray RH, Kigozi G, Serwadda D, Makumbi F, Watya S, Nalugoda F, et al. Male circumcision for HIV prevention in men in Rakai, Uganda: a randomised trial. Lancet. 2007;369:657-66.

4. Bailey RC, Moses S, Parker CB, Agot K, Maclean I, Krieger JN, et al. Male circumcision for HIV prevention in young men in Kisumu, Kenya: a randomised controlled trial. Lancet. 2007;369:643-56.

5. UNAIDS and WHO. Voluntary medical male circumcision. UNAIDS 2019 Reference. Geneva: UNAIDS/WHO; 2019.

6. Carrasco MA, Wilkinson J, Kasdan B, Fleming P. Systematic review of barriers and facilitators to voluntary medical male circumcision in priority countries and programmatic implications for service uptake. Glob Public Health. 2019;14:91-111.

7. Carrasco MA, Grund JM, Davis SM, Ridzon R, Mattingly M, Wilkinson J, et al. Systematic review of the effect of economic compensation and incentives on uptake of voluntary medical male circumcision among men in sub-Saharan Africa. AIDS Care. 2018;30:1071-82.

8. Kaufman MR, Smelyanskaya M, Van Lith LM, Mallalieu EC, Waxman A, Hatzhold $\mathrm{K}$, et al. Adolescent sexual and reproductive health services and implications for the provision of voluntary medical male circumcision: results of a systematic literature review. PLoS ONE. 2016;11:e0149892-e.

9. Farley TM, Samuelson J, Grabowski MK, Ameyan W, Gray RH, Baggaley R. Impact of male circumcision on risk of HIV infection in men in a changing epidemic context - systematic review and meta-analysis. J Int AIDS Soc. 2020;23:e25490.

10. Poland B, Frohlich KL, Cargo M. Context as a fundamental dimension of health promotion program evaluation. In: Potvin L, McQueen DV, editors. Health promotion evaluation practices in the Americas: values and research. New York: Springer; 2008. p. 299-317.

11. Chouinard JA. Understanding relationships in culturally complex evaluation contexts. Evaluation. 2014;20:332-47.

12. GBD 2015 HIV Collaborators. Estimates of global, regional, and national incidence, prevalence, and mortality of HIV, 1980-2015: the Global Burden of Disease Study 2015. Lancet HIV. 2016;3:e361-e87.

13. GBD 2017 HIV Collaborators. Global, regional, and national incidence, prevalence, and mortality of HIV, 1980-2017, and forecasts to 2030, for 195 countries and territories: a systematic analysis for the Global Burden of Diseases, Injuries, and Risk Factors Study 2017. Lancet HIV. 2019;6:e831-e59.

14. UNAIDS. UNAIDS Data 2020. Geneva: UNAIDS; 2020.

15. Cork MA, Wilson KF, Perkins S, Collison ML, Deshpande A, Eaton JW, et al. Mapping male circumcision for HIV prevention efforts in sub-Saharan Africa. BMC Med. 2020;18:189.

16. National AIDS and STI Control Program (NASCOP). National voluntary medical male circumcision strategy 2014/15-2018/19. Nairobi: Government of Kenya; 2015.

17. Davis SM, Hines JZ, Habel M, Grund JM, Ridzon R, Baack B, et al. Progress in voluntary medical male circumcision for HIV prevention supported by the US
President's Emergency Plan for AIDS Relief through 2017: longitudinal and recent cross-sectional programme data. BMJ Open. 2018;8:e021835.

18. World Health Organization. Preventing HIV through safe voluntary medical male circumcision for adolescent boys and men in generalized HIV epidemics: recommendations and key considerations. Geneva: World Health Organization; 2020. https://www.who.int/publications/i/item/978-92-4-000854-0.

19. World Health Organization. Models to inform fast tracking voluntary medical male circumcision in HIV combination prevention: report from World Health Organization and UNAIDS meeting, 23-24 March 2016. Geneva: World Health Organization; 2017.

20. Boden LA, McKendrick IJ. Model-based policymaking: a framework to promote ethical "good practice" in mathematical modeling for public health policymaking. Front Public Health. 2017;5:68.

21. Korenromp E, Bershteyn A, Mudimu E, Weiner R, Bonecwe C, Loykissoonlal D, et al. The impact of the program for medical male circumcision on HIV in South Africa: analysis using three epidemiological models [version 1]. Gates Open Res. 2021;5:15.

22. Kagaayi J, Chang LW, Ssempijja V, Grabowski MK, Ssekubugu R, Nakigozi G, et al. Impact of combination HIV interventions on HIV incidence in hyperendemic fishing communities in Uganda: a prospective cohort study. Lancet HIV. 2019;6: e680-e7.

23. Vandormael A, Akullian A, Siedner M, de Oliveira T, Bärnighausen T, Tanser F. Declines in HIV incidence among men and women in a South African population-based cohort. Nat Commun. 2019;10:5482

24. Loevinsohn G, Kigozi G, Kagaayi J, Wawer MJ, Nalugoda F, Chang LW, et al. Effectiveness of voluntary medical male circumcision for HIV prevention in Rakai, Uganda. Clin Infect Dis. 2020. https://doi.org/10.1093/cid/ciaa1533.

25. Borgdorff MW, Kwaro D, Obor D, Otieno G, Kamire V, Odongo F, et al. HIV incidence in western Kenya during scale-up of antiretroviral therapy and voluntary medical male circumcision: a population-based cohort analysis. Lancet HIV. 2018;5:e241-e9.

26. Makhema J, Wirth KE, Pretorius Holme M, Gaolathe T, Mmalane M, Kadima E, et al. Universal Testing, Expanded Treatment, and Incidence of HIV Infection in Botswana. N Engl J Med. 2019;381:230-42.

27. Reason J. Understanding adverse events: human factors. Qual Health Care. 1995;4:80-89.

28. WHO/UNAIDS Technical Consultation. Male circumcision and HIV prevention: research implications for policy and programming-Montreux, 6-8 March 2007. Geneva: WHO; 2007.

29. Johnson KE, Quinn TC. Update on male circumcision: prevention success and challenges ahead. Curr Infect Dis Rep. 2008;10:243-51.

30. Lucas T, Hines JZ, Samuelson J, Hargreave T, Davis SM, Fellows I, et al. Urethrocutaneous fistulas after voluntary medical male circumcision for HIV prevention-15 African Countries, 2015-2019. BMC Urol 2021;21:1-10.

31. Manentsa M, Mukudu H, Koloane N, Ringane A, Matta E, Martinson NA, et al. Complications of high volume circumcision: glans amputation in adolescents; a case report. BMC Urol. 2019;19:65.

32. Galukande M, Sekavuga DB, Muganzi A, Coutinho A. Fournier's gangrene after adult male circumcision. Int J Emerg Med. 2014;7:37.

33. Dalal S, Samuelson J, Reed J, Yakubu A, Ncube B, Baggaley R. Tetanus disease and deaths in men reveal need for vaccination. Bull World Health Organ. 2016;94:613-21.

34. Nanteza B, Galukande M, Aceng J, Musinguzi J, Opio A, Mbonye AK, et al. The burden of tetanus in Uganda. Springerplus. 2016;5:705.

35. Luseno WK, Field SH, Iritani BJ, Rennie S, Gilbertson A, Odongo FS, et al. Consent challenges and psychosocial distress in the scale-up of voluntary medical male circumcision among adolescents in Western Kenya. AIDS Behav. 2019;23:3460-70.

36. Gilbertson A, Ongili B, Odongo FS, Hallfors DD, Rennie S, Kwaro D, et al. Voluntary medical male circumcision for HIV prevention among adolescents in Kenya: Unintended consequences of pursuing service-delivery targets. PLoS One. 2019;14:e0224548.

37. Feldacker C, Murenje V, Makunike-Chikwinya B, Hove J, Munyaradzi T, Marongwe $\mathrm{P}$, et al. Balancing competing priorities: quantity versus quality within a routine, voluntary medical male circumcision program operating at scale in Zimbabwe. PLoS One. 2020;15:e0240425.

38. Galukande M, Kahendehe C, Buuza E, Sekavuga DB. A rare but important adverse event associated with adult voluntary medical male circumcision: prolonged bleeding. Int J Emerg Med. 2015;8:8.

39. Van Lith LM, Mallalieu EC, Patel EU, Dam KH, Kaufman MR, Hatzold K. et al. Perceived quality of in-service communication and counseling among adolescents undergoing voluntary medical male circumcision. Clin Infect Dis. 2018;66 Suppl 3:S205-S12.

40. Schenk KD, Friedland BA, Sheehy M, Apicella L, Hewett PC. Making the cut: Evidence-based lessons for improving the informed consent process for 
voluntary medical male circumcision in Swaziland and Zambia. AIDS Educ Prev. 2014:26:170-84.

41. Kalichman S, Eaton L, Pinkerton S. Circumcision for HIV prevention: failure to fully account for behavioral risk compensation. PLoS Med. 2007;4:e138

42. Agot KE, Kiarie JN, Nguyen HQ, Odhiambo JO, Onyango TM, Weiss NS. Male circumcision in Siaya and Bondo Districts, Kenya: prospective cohort study to assess behavioral disinhibition following circumcision. J Acquir Immune Defic Syndr. 2007;44:66-70.

43. Kibira SPS, Atuyambe LM, Sandøy IF, Makumbi FE, Daniel M. "Now that you are circumcised, you cannot have first sex with your wife": post circumcision sexual behaviours and beliefs among men in Wakiso district, Uganda. J Int AIDS Soc. 2017;20:21498.

44. Westercamp M, Agot KE, Ndinya-Achola J, Bailey RC. Circumcision preference among women and uncircumcised men prior to scale-up of male circumcision for HIV prevention in Kisumu, Kenya. AIDS Care. 2012;24:157-66.

45. Hogben M, Liddon N. Disinhibition and risk compensation: Scope, definitions, and perspective. Sex Transm Dis. 2008;35:1009-10.

46. Kagaayi J, Kong X, Kigozi G, Ssekubugu R, Kigozi G, Nalugoda F, et al. Selfselection of male circumcision clients and behaviors following circumcision in a service program in Uganda. AIDS. 2016;30:2125-9.

47. Shi CF, Li M, Dushoff J. Evidence that promotion of male circumcision did not lead to sexual risk compensation in prioritized Sub-Saharan countries. PLoS One. 2017; 12:e0175928.

48. Gao Y, Yuan T, Zhan Y, Qian H-Z, Sun Y, Zheng W. et al. Association between medical male circumcision and HIV risk compensation among heterosexual men: a systematic review and meta-analysis. Lancet Glob Health. 2021;9:e932-e41.

49. Serwadda DM, Kigozi G. Does medical male circumcision result in sexual risk compensation in Africa? Lancet. 2021;9:e883.

50. Spees LP, Wirth KE, Mawandia S, Bazghina-Werq S, Ledikwe JH. Sexual risk compensation following voluntary medical male circumcision: results from a prospective cohort study amongst human immunodeficiency virus-negative adult men in Botswana. South Afr J HIV Med. 2020;21:1157.

51. Mattson CL, Campbell RT, Bailey RC, Agot K, Ndinya-Achola JO, Moses S. Risk compensation is not associated with male circumcision in Kisumu, Kenya: a multi-faceted assessment of men enrolled in a randomized controlled trial. PLoS One. 2008;3:e2443.

52. Westercamp N, Agot K, Jaoko W, Bailey RC. Risk compensation following male circumcision: results from a two-year prospective cohort study of recently circumcised and uncircumcised men in Nyanza Province, Kenya. AIDS Behav. 2014;18:1764-75.

53. Gray R, Kigozi G, Kong X, Ssempiija V, Makumbi F, Wattya S, et al. The effectiveness of male circumcision for HIV prevention and effects on risk behaviors in a posttrial follow-up study. AIDS. 2012;26:609-15.

54. Kong X, Kigozi G, Nalugoda F, Musoke R, Kagaayi J, Latkin C, et al. Assessment of changes in risk behaviors during 3 years of posttrial follow-up of male circumcision trial participants uncircumcised at trial closure in Rakai, Uganda. Am J Epidemiol. 2012;176:875-85.

55. Govender K, George G, Beckett S, Montague C, Frohlich J. Risk compensation following medical male circumcision: Results from a 1-Year prospective cohort study of young school-going men in KwaZulu-Natal, South Africa. Int J Behav Med. 2018;25:123-30.

56. Gray GE, Metch B, Churchyard G, Mlisana K, Nchabeleng M, Allen M, et al. Does participation in an HIV vaccine efficacy trial affect risk behaviour in South Africa? Vaccine. 2013;31:2089-96.

57. Peltzer K, Simbayi L, Banyini M, Kekana Q. HIV risk reduction intervention among medically circumcised young men in South Africa: a randomized controlled trial. Int J Behav Med. 2012;19:336-41.

58. Garenne M, Matthews A. Voluntary medical male circumcision and HIV in Zambia: expectations and observations. J Biosoc Sci. 2020;52:560-72.

59. Wilson NL, Xiong W, Mattson CL. Is sex like driving? HIV prevention and risk compensation. J Dev Econ. 2014;106:78-91.

60. Chillag K, Guest G, Bunce A, Johnson L, Kilmarx PH, Smith DK. Talking about sex in Botswana: social desirability bias and possible implications for HIV-prevention research. Afri. J AIDS Res. 2006;5:123-31.

61. Kelly CA, Soler-Hampejsek E, Mensch BS, Hewett PC. Social desirability bias in sexual behavior reporting: evidence from an interview mode experiment in rural Malawi. Int Perspect Sex Reprod Health. 2013;39:14.

62. Krumpal I. Determinants of social desirability bias in sensitive surveys: a literature review. Qual Quant. 2013;47:2025-47.

63. Grund JM, Hennink MM. A qualitative study of sexual behavior change and risk compensation following adult male circumcision in urban Swaziland. AIDS Care. 2012;24:245-51.

64. Andersson N, Cockcroft A. Male circumcision, attitudes to HIV prevention and HIV status: a cross-sectional study in Botswana, Namibia, and Swaziland. AIDS Care. 2012;24:301-9.
65. Kalichman S, Mathews C, Kalichman M, Eaton LA, Nkoko K. Male circumcision for HIV prevention: awareness, risk compensation, and risk perceptions among South African women. Glob Public Health. 2018;13:1682-90.

66. Eaton LA, Cain DN, Agrawal A, Jooste S, Udemans N, Kalichman SC. The influence of male circumcision for HIV prevention on sexual behaviour among traditionally circumcised men in Cape Town, South Africa. Int J STD AIDS. 2011;22:674-9.

67. White RG, Glynn JR, Orroth KK, Freeman EE, Bakker R, Weiss HA, et al. Male circumcision for HIV prevention in sub-Saharan Africa: who, what and when? AIDS. 2008;22:1841-50.

68. Fleming PJ, Doshi M, Harper GW, Otieno F, Bailey RC. Integration of voluntary male medical circumcision for HIV prevention into norms of masculinity: findings from Kisumu, Kenya. Cult Health Sex. 2020;23:1-13.

69. Fish M, Shahvisi A, Gwaambuka T, Tangwa GB, Ncayiyana D, Earp BD. A new Tuskegee? Unethical human experimentation and Western neocolonialism in the mass circumcision of African men. Dev World Bioeth. 2020. https://doi.org/ 10.1111/dewb.12285.

70. Morris B, Wamai R, Henebeng E, Tobian A, Klausner J, Banerjee J, et al. Estimation of country-specific and global prevalence of male circumcision. Popul Health Metr. 2016;14:1-13.

71. Weiss H, Polonsky J, Bailey R, Hankins C, Halperin D, Schmid G. Male circumcision: global trends and determinants of prevalence, safety, and acceptability. Geneva: World Health Organization and the Joint United Nations Programme on HIV/AIDS (UNAIDS); 2007.

72. Rennie S, Gilbertson A, Hallfors D, Luseno WK. Ethics of pursuing targets in public health: The case of voluntary medical male circumcision for HIVprevention programs in Kenya. J Med Ethics. 2020. https://doi.org/10.1136/ medethics-2020-106293.

73. Berer M. Male circumcision for HIV prevention: perspectives on gender and sexuality. Reprod Health Matters. 2007;15:45-48.

74. Berer M. Male circumcision for HIV prevention: what about protecting men's partners? Reprod Health Matters. 2008;16:171-5.

75. Berer M. Male circumcision and risk of HIV in women. Lancet. 2009;374:1497-8.

76. Wawer MJ, Makumbi F, Kigozi G, Serwadda D, Watya S, Nalugoda F, et al. Circumcision in HIV-infected men and its effect on HIV transmission to female partners in Rakai, Uganda: a randomised controlled trial. Lancet. 2009;374:229-37.

77. Dzinamarira T, Nachipo B, Phiri B, Musuka G. COVID-19 vaccine roll-out in South Africa and Zimbabwe: Urgent need to address community preparedness, fears and hesitancy. Vaccines. 2021;9:250.

78. Blair RA, Morse BS, Tsai LL. Public health and public trust: Survey evidence from the Ebola Virus Disease epidemic in Liberia. Soc Sci Med. 2017;172:89-97.

79. Østergaard LR. Trust matters: a narrative literature review of the role of trust in health care systems in sub-Saharan Africa. Glob Public Health. 2015;10:1046-59.

80. Dowsett GW, Couch M. Male circumcision and HIV prevention: is there really enough of the right kind of evidence? Reprod Health Matters. 2007;15:33-44.

81. Collier R. The studies that launched a thousand snips. CMAJ. 2012;184:E37-E38.

82. Gwandure $C$. The ethical concerns of using medical male circumcision in HIV prevention in Sub-Saharan Africa. SAJBL. 2011;4:89-94.

83. Giami A, Perrey C, de Oliveira Mendonça AL, de Camargo KR. Hybrid forum or network? The social and political construction of an international 'technical consultation': Male circumcision and HIV prevention. Glob Public Health. 2015;10:589-606.

84. Brives $C$. The myth of a naturalised male circumcision: heuristic context and the production of scientific objects. Glob Public Health. 2018;13:1599-15611.

85. Rudrum S. Promoting male circumcision as HIV prevention in sub-Saharan Africa: an evaluation of the ethical and pragmatic considerations of adopting a demand creation approach. Glob Public Health. 2020;15:1349-63.

86. Mhagama $P$, Makono $P$, Tsitsi $C$. Communication-related factors influencing the uptake of voluntary medical male circumcision among men in Lilongwe Urban. Malawi Cogent Med. 2021;8:1892289.

87. L'Engle K, Lanham M, Loolpapit M, Oguma I. Understanding partial protection and HIV risk and behavior following voluntary medical male circumcision rollout in Kenya. Health Educ Res. 2014;29:122-30.

88. Kaufman MR, Patel EU, Dam KH, Packman ZR, Van Lith LM, Hatzold K. et al. Counseling received by adolescents undergoing voluntary medical male circumcision: Moving toward age-equitable comprehensive human immunodeficiency virus prevention measures. Clin Infect Dis. 2018;66 Suppl 3:S213-S20.

89. WHO/UNAIDS. New data on male circumcision and HIV prevention: policy and programme implications: WHO/UNAIDS Technical Consultation, Male Circumcision and HIV Prevention: Research Implications for Policy and Programming, Montreux, 6-8 March 2007. Geneva: WHO/UNAIDS; 2007.

90. Boyee D, Peacock E, Plotkin M, Hellar A, Mahler H, Edouard E, et al. What messages are adolescent voluntary medical male circumcision (VMMC) clients getting and how? Findings from an observational study in Tanzania. AIDS Behav. 2017;21:1383-93. 
91. Schenk KD, Friedland BA, Apicella L, Sheehy M, Munjile $K$, Hewett PC. On the cutting edge: Improving the informed consent process for adolescents in Zambia undergoing male circumcision for HIV prevention. Vulnerable Child Youth Stud. 2012;7:116-27.

92. Strode A, Slack C, Essack Z. Child consent in South African law: implications for researchers, service providers, and policy-makers. S Afr Med J. 2010;100:247-9.

93. Bastien S, Kajula LJ, Muhwezi WW. A review of studies of parent-child communication about sexuality and HIV/AIDS in sub-Saharan Africa. Reprod Health. 2011;8:1-17.

94. De Zwart F. Unintended but not unanticipated consequences. Theory Soc. 2015;44:283-97.

95. Merton RK. The unanticipated consequences of purposive social action. Am Socio Rev. 1936;1:894-904.

96. Oliver K, Lorenc T, Tinkler J, Bonell C. Understanding the unintended consequences of public health policies: the views of policymakers and evaluators. BMC Public Health. 2019;19:1-9.

97. The assembly of the Ninth International Symposium on Circumcision GIHR. Petition to the Gates Foundation from the Assembly of the Ninth International Symposium on Circumcision, Genital Integrity \& Human Rights, at the University of Washington, Seattle, Washington, USA, August 24-26, 2006. https://www.doctorsopposingcircumcision.org/wpcontent/uploads/2020/10/ Gates_Foundation_Petition_08-2006.pdf.

98. UNAIDS/CAPRISA. UNAIDS/CAPRISA Consultation on Social Science Perspectives on Male Circumcision for HIV Prevention, 18-19 January, 2007 Summary Report. https://data.unaids.org/pub/agenda/2007/ 20070303 male circumcision report en.pdf (2007).

99. Fleming PJ, Barrington C, Pearce LD, Lerebours L, Donastorg Y, Brito MO. "I feel like more of a man": a mixed methods study of masculinity, sexual performance, and circumcision for HIV prevention. J Sex Res. 2017;54:42-54.

100. Kass NE. An ethics framework for public health. Am J Public Health. 2001;91:1776-82.

\section{ACKNOWLEDGEMENTS}

We are grateful to Bonita Iritani and Shane Hartman for their assistance on this paper. Research reported in this publication was supported by funding from the National Institute of Mental Health and the National Institute of Allergy and Infectious Diseases of the National Institutes of Health under Award Number R01MH102125 (Luseno, W. $\mathrm{K}$., PI). The content is solely the responsibility of the authors and does not necessarily represent the official views of the National Institutes of Health.

\section{AUTHOR CONTRIBUTIONS}

$W K L, S R$, and AG contributed equally to conceptualizing the paper, conducting literature searches, identifying and reviewing articles to be included, writing the original draft, and editing and revising subsequent drafts.

\section{COMPETING INTERESTS}

The authors declare no competing interests.

\section{ADDITIONAL INFORMATION}

Correspondence and requests for materials should be addressed to Winnie Kavulani Luseno.

Reprints and permission information is available at http://www.nature.com/ reprints

Publisher's note Springer Nature remains neutral with regard to jurisdictional claims in published maps and institutional affiliations. 